\title{
Culex gnomatos a New Species of the Spissipes Section of Culex (Melanoconion) (Diptera: Culicidae) from the Amazon Region
}

\author{
Maria Anice Mureb Sallum $/{ }^{+}$, Rosa Sá Gomes Hutchings*, Ruth Leila \\ Menezes Ferreira*
}

\begin{abstract}
Departamento de Epidemiologia, Núcleo de Pesquisa Taxonômica e Sistemática em Entomologia Médica, Faculdade de Saúde Pública, Universidade de São Paulo, Av. Dr. Arnaldo 715, 01246-904 São Paulo, SP, Brasil *Coordenação de Pesquisas em Entomologia, Instituto Nacional de Pesquisas da Amazônia, Caixa Postal 478, 69011-970 Manaus, AM, Brasil
\end{abstract}

The adult male and female of Culex (Melanoconion) gnomatos $n$. sp. are described and compared with Cx. vomerifer Komp, Cx. portesi Senevet \& Abonnenc and Cx. sacchettae Sirivanakarn \& Jakob. Available data about distribution and bionomics are presented.

Key words: Culicidae - Melanoconion s. gen. - Culex gnomatos - new species

The Spissipes Section of Culex (Melanoconion) was the subject of a recent revision by Sallum and Forattini (1996), where the adult and the male genitalia of 22 species were studied. However, while examining specimens of Melanoconion from the "Parque Nacional do Jaú", State of Amazonas, Brazil, and comparing them with specimens of $C x$. vomerifer Komp, $C x$. portesi Senevet \& Abonnenc and $C x$. sacchettae Sirivanakarn \& Jakob we noted some unusual features in the adults and male genitalia. Here, we present the description of a new Amazonian region species of the Spissipes Section.

\section{TAXONOMIC TREATMENT}

\section{Culex (Melanoconion) gnomatos $\mathrm{n}$. sp.}

Diagnosis - A small dark brown species resembling Cx. vomerifer Komp, but differing in not having patch of minute, light golden setae on middle portion of mesepimeron and a hyaline expansion near middle region of ventral side of gonostylus.

Female - Body mostly covered with brownish black scales. Head: antenna dark, length about 1.89 $\mathrm{mm}$; flagellum normal, whorls with 6 setae. Proboscis dark-scaled, length 1.47-1.67 mm

Supported by grants no. 95/7157-2, Fundação de Amparo à Pesquisa do Estado de São Paulo and PPI-3400, Instituto Nacional de Pesquisa da Amazônia, Brazil. ${ }^{+}$Corresponding author. Fax: +55-11-282.1898

Received 9 August 1996

Accepted 16 September 1996 (mean $=1.57 \mathrm{~mm}$ ). Maxillary palpus dark-scaled, length $0.29-0.33 \mathrm{~mm}$ (mean $=0.31 \mathrm{~mm}$ ), about 0.20 length of proboscis. Vertex with narrow falcate scales and small patches of broad, appressed, grayish spatulate scales laterally, narrow falcate scales dark on median dorsal region, becoming dingy white on lateral regions; forked scales totally dark; occiput with some whitish narrow falcate scales. Cibarium (Figs 1D-F, 2): cibarium length about $168 \mu \mathrm{m}$; cibarial bar concave, dorsal surface and posterior margin with small spicules; about 12-15 teeth; tooth length about $13 \mu \mathrm{m}$; line of origin not evident; hollow area of teeth small, restricted to base. Cibarial dome nearly pentagonal, concavoconvex, surface with long, triangular, pointed, posteriorly directed denticles; 4 palatal setae, $1-3$ on each lateral edges of anterior hard palate; 3 , 4 sensilla trichodea on each side. Thorax (Fig. 1A-C): integument brown to brownish black; scutum with narrow falcate dark brown scales, scales with reddish reflections; scutal setae prominent, black with reddish or golden reflections; acrostichal setae present only on posterior end of the area; 2,3 pairs of alveoli present on anterior region of prescutellar area. Scutellar scales similar in color and size to scutal scales; lateral lobes of scutellum each with 3, 4 large setae, median lobe with 6 long setae. Antepronotum without scales, with scattered black setae. Postpronotum with narrow falcate dark scales on dorsal margin and 4, 5 dorsal setae on posterodorsal margin. Pleural integument pale yellow, antepronotal, postpronotal, proepisternal, subspiracular, postspiracular, prespiracular and prealar areas dark brown; mesokatepisternum dark brown from upper corner to anteroventral area, pale yellow along posterior area; mesepimeron dark 

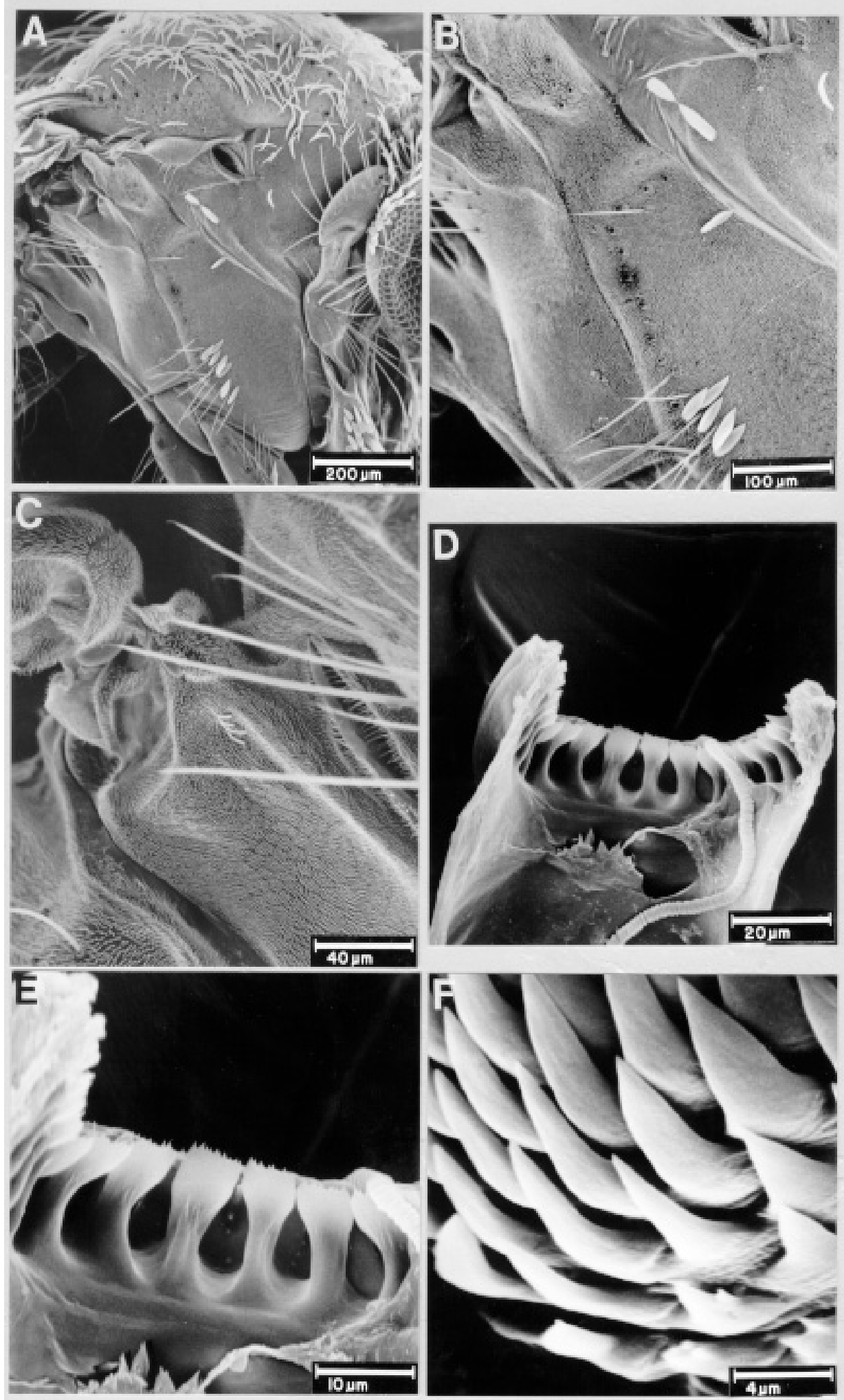

Fig.1: Culex gnomatos, female - A, B: lateral aspect of thorax showing the absence of patch of minute setae on median region of mesepimeron and the dorsal lower mesokatepisternal setae disposed in double, irregular rows. C: minute metepisternal setae. D, E: dorsal aspect of cibarial armature. F: cibarial dome. 
brown on upper and lower areas, middle area pale yellow; pleural setae dark brown with reddish reflections, the less developed lower mesokatepisternal setae light brown: 10-12 upper proepisternal, 4-6 prealar, 12-15 upper mesokatepisternal, 14-17 lower mesokatepisternal, 1215 upper mesepimeral, 1, 2 lower mesepimeral and 4 minute metepisternal; most dorsal lower mesokatepisternal setae disposed in 2 irregular rows. Pleura with patch of nearly colorless scales on lower posterior margin of mesokatepisternum, occasionally with 2,3 scales on upper corner. Wing: dark-scaled, length 2.35-2.68 mm (mean $=2.47$ $\mathrm{mm}$ ); cell $\mathrm{R}_{2} 4.16-5.36$ of vein $\mathrm{R}_{2+3}$ (mean=4.86); cell $\mathrm{M}_{2} 0.76$ of cell $\mathrm{R}_{2}$; subcosta intersects costa at level of furcation of $\mathrm{R}_{2+3}$. Dorsal scaling: appressed spatulate scales on costa, subcosta, $R, R_{1}, R_{4+5}$, $\mathrm{M}_{1+2}, \mathrm{M}_{3+4}, \mathrm{Cu}, \mathrm{Cu}_{1}, \mathrm{Cu}_{2}$ and $1 \mathrm{~A}$; linear plume scales on $R_{s}, R_{2+3}$ and $M$; inclined narrow spatulate scales on $\mathrm{R}_{2}$ and $\mathrm{R}_{3}$; remigium with 1,2 distal setae. Ventral scaling: appressed spatulate scales on costa, subcosta, proximal 0.5 of $\mathrm{R}_{1}, \mathrm{R}_{\mathrm{s}}, \mathrm{R}_{2+3}$, proximal 0.3 of $R_{2}$, proximal 0.3 of $R_{3}, M$ and proximal 0.3 of $\mathrm{M}_{1+2}$; linear plume scales on proximal 0.2 of $\mathrm{R}_{4+5}$, proximal 0.3 of $\mathrm{Cu}_{1}, \mathrm{Cu}_{2}$ and on middle of $1 \mathrm{~A}$; inclined narrow spatulate scales on distal 0.5 of $\mathrm{R}_{1}, \mathrm{R}_{2}, \mathrm{R}_{3}$, distal 0.8 of $\mathrm{R}_{4+5}$, distal 0.7 of $\mathrm{M}_{1+2}, \mathrm{M}_{3+4}$ and distally on $1 \mathrm{~A} ; \mathrm{Cu}$ and proximal 0.5 of $1 \mathrm{~A}$ devoid of scales. Halter: scabellum and pedicel whitish, capitellum darkscaled. Legs: anterior surface of forecoxa with patch of dark scales, anterior surface of midcoxa with vertical line of dark scales, hindcoxa with vertical line of colorless scales; anteroventral surfaces of fore- and midtrochanter with dark scales, posteroventral surface of fore- and midtrochanter with whitish scales, hindtrochanter white-scaled. Femora broadly covered with light cream scales on ventral surface; remainder dark-scaled. Tibiae and tarsi dark-scaled. Abdomen: tergum I with a posteromedian patch of dark scales; terga II-VIII dark-scaled with basolateral patches of whitish scales. Sternum II with whitish scales, sterna III VII dark-scaled with basal bands of white scales; sternum VIII without scales. Genitalia (Fig. 2): tergum IX narrow, with small flattened lobes bearing 6-9 slender setae. Upper vaginal lip distinct, narrow; lower vaginal lip and insula indistinct, with 8,9 clustered insular setae. Upper vaginal sclerite somewhat rectangular in outline. Postgenital lobe nearly trapezoidal, with 9-11 setae on either side of midline, mostly on ventral surface.

Male - Similar to female except for the following sexual differences. Head: antenna strongly verticillate; length about $1.59 \mathrm{~mm}$; maxillary palpus dark-scaled, length $2.50 \mathrm{~mm}$; palpomeres 4,5 densely setose, palpomere 3 with 7 strong setae on outer apical area. Abdomen: terga II-VI dark-scaled with basolateral patches of whitish scales (remaining terga removed with genitalia). Sternum II white-scaled, sterna III-VI dark-scaled with basal bands of whitish scales. Genitalia (Fig. 2): tergum IX lobes small, somewhat triangular in outline, lobes widely separated with few slender setae. Gonocoxite stocky, outer margin convex, inner nearly straight; ventrolateral setae strongly developed, ventromesal surface with small setae scattered from base to level of subapical lobe, setae stronger basally, lateral surface with patch of short sparse setae (lsp) at level of subapical lobe, tergomesal surface without seta or with 1, 2 setae proximal to subapical lobe; proximal part of ventrolateral surface without scales; subapical lobe distinctly divided, divisions well separated, proximal division entire, elongate, columnar, with 2 long, robust, sinuous, apically hooked setae (setae $a$ and $b$ ) and bearing 1, 2 slender, short setae on basal half of lateral side; seta $a$ inserted slightly basal to seta $b$, seta $b$ long, rodlike, expanded on subapical portion; distal division with 8 setae: a long, strong, apically hooked seta $(h)$, this hook truncated at apex, a pointed, saberlike seta $(s)$, a longer, stronger saberlike seta $(s)$, a broad, asymmetrical foliform seta $(l)$, inserted laterally to the longer saberlike seta, strongly sclerotized on proximal area, 4 subequal, appressed setae, one of these with a small hook at apex, the others rounded at tip $(f)$. Gonostylus slender, curved, widened distally on lateral side, bearing a wrinkled subapical crest on ventral side, widened part with 2 setae on mesal side; apical snout, elongate, gonostylar claw short, leaflike. Phallosome with lateral plates and aedeagal sclerites equivalent in length; aedeagal sclerite broad and curved in lateral view; distal part of lateral plate without apical process, ventral and lateral processes present, lateral process strong, tapered and pointed, ventral process shorter, bifid; base of lateral plate with a stout dorsal process. Aedeagal sclerite not connected by dorsal aedeagal bridge. Proctiger elongate; paraproct narrowed distally, expanded basally; crown with row of about 7 simple blades. Cercal sclerite long and narrow; 2,3 cercal setae. Tergum X large, somewhat rectangular in outline.

Type data - Holotype , with associated genitalia on slide, bearing the following collection data: BRAZIL, State of Amazonas, Novo Airão County, Parque Nacional do Jaú, Miratucu River, 26, 27 Jul 1995, coll. Hutchings et al., collected with UV light trap, in forest, deposited in the Entomological Collection of Instituto Nacional de Pesquisas da Amazônia (INPA-CPEN). Paratypes (31 11 ): 

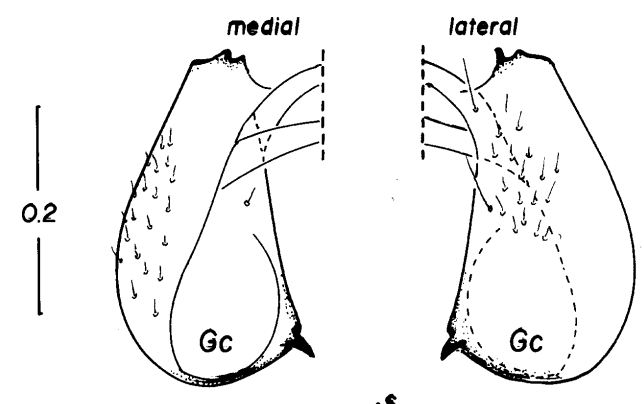

Cx. (Mel.) gnomatos (Amazonas, Brazil)

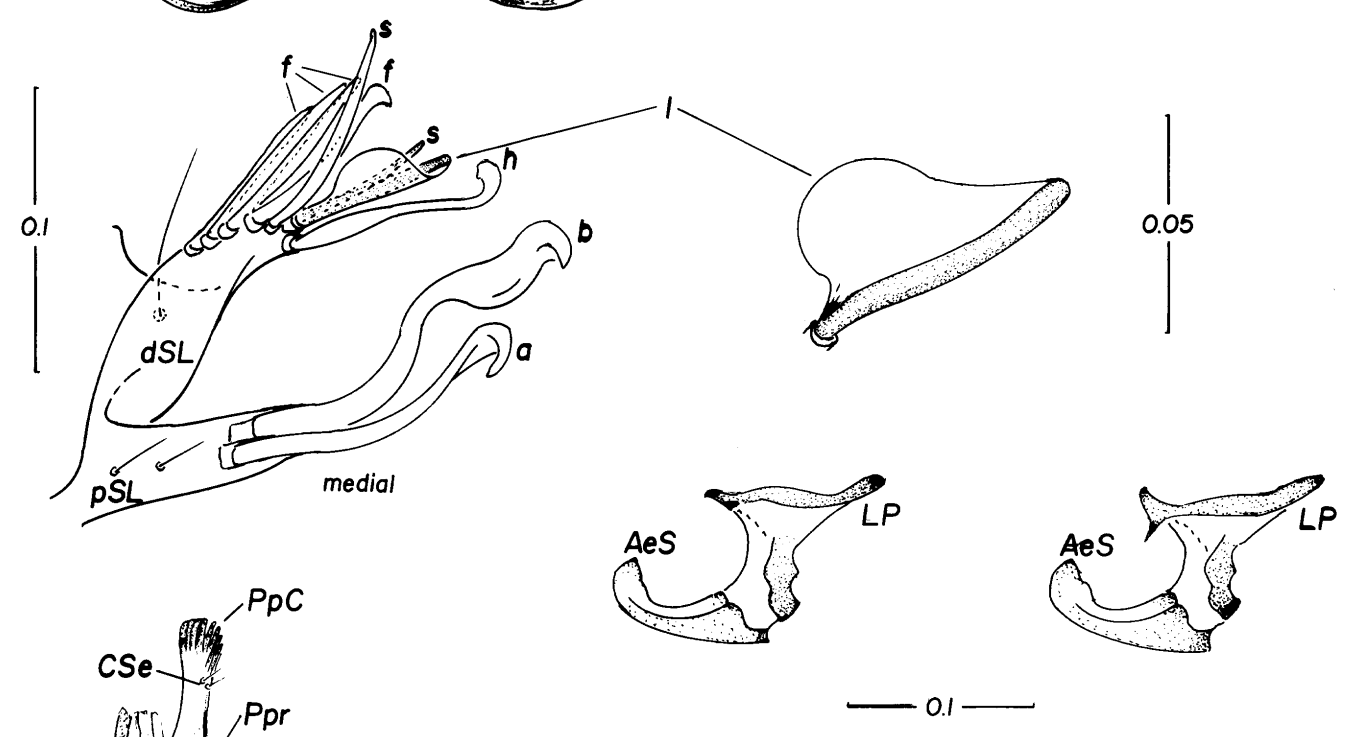

1
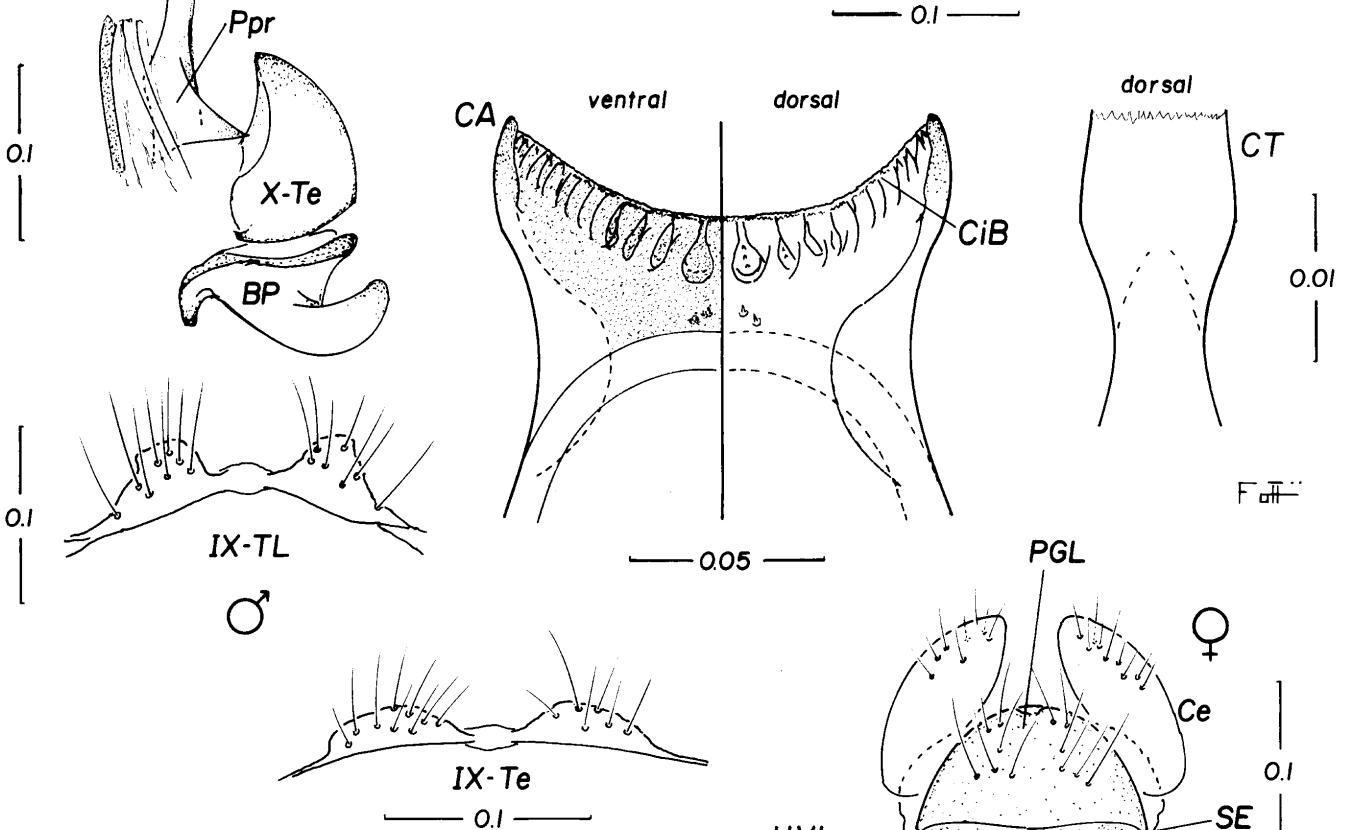

Y

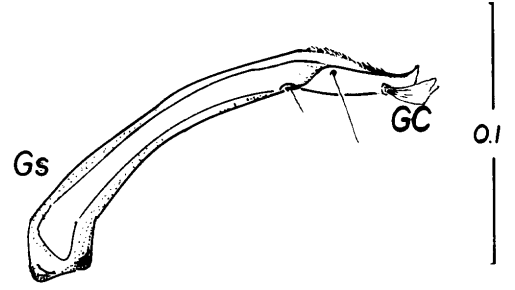


1 with associated genitalia on slide; 24 in pins; 3 in pins with associated cibaria on slides, 4 mounted on slides, with associated genitalia, same data as holotype, but differing as follows: 28,29 Jul 1995, 3 ; collected in Shannon trap supplemented with light, 26 Jul 1995, 4 ; Carabinani River, 1 ${ }^{\circ} 59^{\prime}$ S/6132' W, 29 Jul 1995, coll. Sallum \& Hutchings, 21 cib; 1 Aug 1995, 2 ; collected in CDC light trap, 7, 8 Apr 1994, Coll. Ferreira \& Hutchings, 3 in pins 1 mounted on slide; 10, 11 Apr 1994, 1 ; 11, 12 Apr 1994, 1 1 cib; 12, 13 Apr 1994, $1 \quad 1$ cib; 13, 14 Apr 1994, 1 ; 14, 15 Apr 1994, 3 ; 15, 16 Apr 1994, 5 in pins 3 mounted on slides; collected in Malaise trap, 8-10 Apr 1994, $1 \quad 1 \quad$ G; Miriti River, 2 $18^{\prime}$ 'S/64³9' W, 5, 6 Jun 1994, coll. Ferreira, CDC-LT, 1 (deposited in the Entomological Collection of the Department of Epidemiology, School of Public Health (FSP - USP) and INPA-CPEN).

Distribution - Known from the Amazon region, State of Amazonas, Brazil.

Bionomics - Little is known about this species. Adults were collected in Shannon trap supplemented with light, CDC light traps, UV light trap and malaise trap in primary rain forest.

Etymology - From the Greek gnomatos, meaning "mark". Culex gnomatos is named for the characteristic aspect of the foliform seta $l$ on the distal division of the subapical lobe of gonocoxite.

\section{DISCUSSION}

According to Sallum and Forattini (1996) the Vomerifer Group can be separated from the other groups of the Spissipes Section of Culex (Melanoconion) by features of the adults and male genitalia. Among the distinguishing features of the male genitalia they cited the presence of a hyaline, triangular expansion near middle of ventral side of gonostylus. Although $C x$. gnomatos does not show any evidence of having this character, it can be recognized as a member of the Vomerifer Group by possessing all other characteristics which make the recognition of the group possible.

Culex gnomatos differs from $C x$. vomerifer and $C x$. portesi in possessing the mesokatepisternum dark brown from upper corner to the anteroventral area, pale yellow along posterior area and subspiracular area dark, from $C x$. portesi in having dark spots on upper and lower areas of mesepimeron, prealar knob, postpronotum and subspiracular area and in possessing anterior surface of forecoxa with patch of dark scales, from $C x$. vomerifer in not having a patch of minute, light golden setae on middle portion of mesepimeron, and from $C x$. sacchettae in having hindtarsomeres without pale rings at joints and 5 entirely darkscaled. The cibarial armature of $C x$. gnomatos differs from $C x$. sacchettae in having cibarial bar with sparse spicules on dorsal surface and posterior margin, cibarial tooth somewhat rectangular in outline, distal part not very enlarged and apical portion small, and from $C x$. vomerifer and $C x$. portesi it seems to be indistinguishable. The male genitalia of $C x$. gnomatos differs from $C x$. vomerifer, $C x$. portesi and $C x$. sacchettae in not having a hyaline expansion near middle of ventral side of gonostylus, in having the apical hook of seta $h$ truncated at apex and one of seta $f$ ending in a small hook, the other 3 setae $f$ rounded at apex, from $C x$. portesi in having tergal IX lobes small, conical, widely separated, with small slender setae and from $C x$. sacchettae in having tergomesal surface of gonocoxite proximal to subapical lobe with 1, 2 small setae.

Culex gnomatos can be distinguished from the other species of the Spissipes Section of Melanoconion by adding the following modification to the keys proposed by Sallum and Forattini (1996). The numeration of the adult and male genitalia keys must be adjusted from the point where a new dichotomy has been introduced to the end of the key.

\section{Adult}

19(18). Mesepimeron dark on upper and lower areas; mesokatepisternum with a dark brown patch on much of anterior area ......................... gnomatos Mesepimeron totally yellowish; mesokatepisternum totally yellowish or with dark spot only on anterior portion

\section{Male genitalia}

10(4). Gonostylus with submedian triangular, hyaline expansion on ventral side ............................11 Gonostylus without hyaline expansion near middle on ventral side ..................................13

13(10). Seta $h$ of distal division of subapical lobe of gonocoxite with a truncate hook at apex; one of setae $f$ hooked at tip gnomatos Seta $h$ of distal division of subapical lobe of gonocoxite with a pointed hook at apex; setae $f$ pointed or truncated at tip, never hooked ........14

\section{ACKNOWLEDGMENTS}

To Prof. Dr Oswaldo Paulo Forattini for producing the illustrations, critical comments and suggestions on the manuscript, to INPA and Fundação Vitória Amazônica for providing our trip to Parque Nacional do Jaú, to DC Flores for labelling the illustrations, and to RP Domingues for typing the manuscript.

\section{REFERENCE}

Sallum MAM, Forattini OP 1996. Revision of the Spissipes Section of Culex (Melanoconion) (Diptera: Culicidae). J Amer Mosq Control Assoc 12: 517 600. 
220 Culex gnomatos n. sp. - MAM Sallum et al. 